\title{
Cástulo en las fuentes geográficas árabes: evidencias de un santuario altomedieval en su territorio
}

\author{
Cástulo in arabic geographic sources: an evidence of a high medieval \\ sanctuary in its territory
}

María Dolores Rosado Llamas*

\begin{abstract}
RESUMEN
Dado que las referencias a Cástulo en las fuentes geográficas árabes son prácticamente inexistentes, este artículo quiere dar a conocer la información que, sobre esta ciudad, proporciona un autor árabe medieval: al-Qazwinī (s. XIII), cuyas noticias sobre Cástulo no han sido traducidas hasta ahora; así como, a la luz de este texto, reinterpretar la información que proporcionan el resto de geógrafos árabes porque, gracias a al-Qazwīnī, podemos inferir la existencia de un santuario rupestre y probable eremitorio altomedieval, visigodo y/o mozárabe, en el propio Cástulo o en su territorio.
\end{abstract}

Palabras clave: Cástulo, al-Andalus, fuentes geográficas árabes, al-Qazwīnī, santuarios y eremitorios altomedievales, visigodos, mozárabes, valle del Guadalimar.

\section{INTRODUCCIÓN}

Si bien las referencias geográficas a Cástulo en las fuentes árabes medievales son escasas, no podemos decir lo mismo sobre las referencias históricas que, para el periodo islámico, son un poco más numerosas $y$, aunque tampoco demasiadas, ya fueron señaladas en su día por estudiosos locales (CONTRERAS DE LA PAZ, 1967), prestigiosos arqueólogos (GÓNGORA, 1860; TORRES BALBÁS, 1957: 117-127; CASTILLO ARMENTEROS, 1997) y arabistas (VALLVÉ BERMEJO 1969: 72-73; AGUIRRE SÁBADA y JIMÉNEZ MATA 1979: 118, 134, 143).

\footnotetext{
* Doctora en Historia Medieval. Profesora de Historia EE.SS.
}

\begin{abstract}
Due to the difficulty for finding references to Cástulo in Geographic Arabic sources, the aim of this article is to show certain information given by an Arab author: al-Qazwīni (13th century), offering the translation of his text into Spanish, and to this extend, reconsider news given by the corpus of Islamic Geographic authors about Cástulo because, thanks to al-Qazwinī, we can admit the existence of one Visigothic or Mozarabic sanctuary, probably an hermitage in Cástulo itsef or in its interland.
\end{abstract}

Key words: Cástulo, al-Andalus, Arabic Geographic sources, al-Qazwīnī, medieval sanctuaries and hermitages, Mozarabians, Guadalimar Valley.

Para empezar debemos señalar que el nombre árabe de Cástulo es Qasțulūna, aunque también puede encontrarse en la bibliografía vocalizado como Qastalūna (TORRES BALBÁS 1957: 117). La evolución fonética del topónimo ha sido explicada (JACINTO GARCÍA, 2006: 1010) mediante un proceso característico propio de "numerosos topónimos prerromanos" en los que el nombre se declinaba con un sufijo nasal, así Castulo se convertía en Castulona, como Carmo lo hacía en Carmona o Barcino en Barcinona. En las fuentes cristianas, el nombre siguió evolucionando y el topónimo árabe se deformó convirtiéndose en la dehesa o cortijo de Cazlona y el Molino de 
Caldona (MADOZ 1851: 6, 253-254; CHOCLÁN SABINA 2012: 29).

\section{LA DECADENCIA DE QASṬULŪNA: DE MADĪNA A ḤIȘN}

La primera referencia histórica a Qasțulūna en las fuentes árabes la encontramos durante la época de la conquista de al-Andalus. Algunos autores (AGUIRRE SÁDABA y JIMÉNEZ MATA 1979: 42; HERNÁNDEZ GIMÉNEZ, 1964: 13-14) mencionan el paso de Tāriq por las inmediaciones de Cástulo en el año 711 cuando se encaminaba desde Écija hacia Toledo, tras haberse desviado probablemente por Mentesa. Concretamente, el paso por Cástulo se efectuaría por el llamado Vado de la Conquista o Majādat al-Fath situado en las inmediaciones de la ciudad, en la confluencia del río Guadalimar con el arroyo Lupión. Desde allí, las tropas musulmanas tendrían varias opciones para franquear Sierra Morena en su camino hacia Toledo.

La segunda referencia a Qastulūna se data en la primavera del año 755, poco antes de la llegada a la Península del príncipe omeya 'Abd al-Rahmān I y la instauración de un emirato independiente en al-Andalus. El contexto es el de la lucha entre dos wālíes o gobernadores de al-Andalus: Yūsuf al-Fihrī y al-Șumayl que habían fraccionado el territorio en torno a dos de sus grandes capitales, Córdoba y Zaragoza. Ambas estaban situadas en los dos valles fluviales que habían acogido al grueso de la población árabe (ACIÉN ALMANSA, 1999: 49). De este modo, Yūsuf al-Fihrī acampó junto al Vado de la Victoria en espera de refuerzos para dirigirse contra Zaragoza (Ajbār maŷmu'a 1867: 72-73; HERNÁNDEZ GIMÉNEZ 1964: 3).

Durante el emirato de 'Abd al-Raḥmān I (756-788) volvemos a encontrar noticias sobre Cástulo en las fuentes árabes. En este caso, la ciudad se relaciona con la sublevación del rebelde Abū l-Aswad al-Fihrī ocurrida en el año 168 de la hégira, 784-785 de nuestro calendario. Su padre, Yūsuf al-Fihrī, wālì de al-Andalus entre 746 y 755, había tratado de impedir la proclamación del emir omeya 'Abd
al-Raḥmān I. Treinta años después, el emir mantenía encarcelado en Córdoba al hijo de su antiguo rival. Sin embargo, el astuto Abū l-Aswad, fingiendo estar ciego, logró escapar de la prisión y, atravesando el Guadalquivir a nado, logró hacerse con una montura para escapar a Toledo, ciudad desde la que encabezaría el levantamiento contra 'Abd al-Rahmān I. Los partidarios del rebelde alzado en Toledo se prepararon para atacar Córdoba y escogieron la ciudad de Qastulūna como base de operaciones. El emir omeya salió a buscar a Abū l-Aswad y le derrotó a las afueras de su cuartel general en Cástulo durante una cruenta batalla que es recogida por los Ajbār maŷmu'a o Noticias reunidas sobre la conquista de al-Andalus:

"Por último, se sublevó contra él ['Abd
al-Rahmān I] Mohammad ben Yóçuf Abol
Áswad, viniendo a estacionarse con sus
secuaces junto á Cazlona. El emir salió
contra él y le tuvo cercado algunos días,
hasta que dispersas las tropas del rebel-
de, fue derrotado, con muerte de cuatro
mil de los suyos, huyendo él hácia Coria,
adonde le siguió sin tardanza el Emir, y
entónces se refugió en las escabrosidades.
El Emir se apoderó de su familia, mató a
algunos de los suyos y asoló la comarca,
regresando en seguida. Ésta fue la última
expedición militar del emir Âbdo-r-Rahmen
ben Moâwiya, que murió á los treintay tres
años y tres meses de su mando." (Ajbār
maŷmu'a 1867: 106)

Es de reseñar que el texto árabe original señala que Cástulo conservaba, todavía en esta época, una gran entidad poblacional, según se desprende de un par de datos que no han sido reflejados en la traducción castellana: el primero que Abū I-Aswad reunió allí a sus partidarios del Levante y el segundo que se establecieron en la ciudad de Cástulo "fïman ațba'a-hu min ahl al-Šarq hatà halla madina Qastulūna" (Ajbār maŷmu'a 1867: 117). La primera referencia incide en el hecho de que Cástulo fuera elegida como cuartel general del rebelde, sin duda gracias a su privilegiada situación pues, desde la Antigüedad, se hallaba ubicada en un nudo de 
comunicaciones entre Córdoba y el levante peninsular (AGUIRRE SÁDABA y JIMÉNEZ MATA 1979: 42). La segunda referencia, aunque fuera obviada por el traductor, es muy interesante, ya que el original árabe le concede el rango de madina o ciudad a Cástulo, capaz de albergar, por tanto, a numerosos opositores. Constatándose un fenómeno ya apercibido por el profesor Manuel Acién y es que, para esta primera época de la historia de al-Andalus, no existen apenas husụūn y los principales puntos fortificados son las ciudades (ACIÉN ALMANSA 1989: 143).

Además, la batalla entre Abū l-Aswad y 'Abd al-Raḥmān I en Cástulo no debió ser una simple escaramuza porque se menciona que fallecieron 4.000 seguidores del rebelde y, por otro lado, su importancia está testimoniada por dos evidencias más que proporcionan las fuentes: la predicción de la misma por cierto adivino y un poema conmemorativo. Con respecto al primer dato, sabemos que el encuentro fue vaticinado por un personaje llamado Farqad b. 'Abd Allāh al-Ŷrurasī/Ŷarasī quien anunció la derrota de Abū l-Aswad al-Fihrī en esos parajes junto a la ciudad de Qastulūna. Farqad (MARín 1986: 520) era un asceta y sabio zaragozano que, además de practicar la guerra santa, tenía visiones y cultivaba el 'ilm al-hidtān, ciencia de difícil traducción pero que estaría relacionada con el mundo de lo esotérico y la adivinación. Su augurio también es recogido en los Ajbār maŷmu'a:

"Me han referido algunos maestros que Abó-l-Fath As-Sadforí, el devoto, estaba tan dominado por el afán de la guerra santa, que pasaba el tiempo, unas veces peleando contra los infieles en la frontera de Aragón, y otras en la de Colomera, donde estaba domiciliado. Era grande amigo de Fárkad, el sabio en predecir los sucesos futuros, y cuando marchaba á la frontera, hacia alli la guerra con él, acompañándole después Fárkad en Colomera, de suerte que casi siempre estaban juntos.

\begin{abstract}
Abó-I-Fath solia referir lo siguiente: "Pasé una vez en compañía de Fárkad cerca de la ciudad de Cazlona, distrito de Jaén, y me dijo: En esta ciudad encuentro que ha de acontecer un infausto suceso; nos dirigiremos hácia ella y te lo referiré. Nos acercamos y me contó el suceso de los dos emires Eben Moawiya y Abó-l-Aswad ben Yóçuf, el cual después acaeció como me lo había predicho..." (Ajbār maŷmu'a 1867: 82-83)
\end{abstract}

Esta batalla, que tuvo lugar el 21 de septiembre de 784, fue además inmortalizada por un poeta maldito, Abū l-Majši ${ }^{1}$, cuyas agrias sátiras, especialmente una en la que llamó bizco al emir Hišām I, le costaron perder la lengua y los ojos. Abū l-Majšì compuso un poema conmemorativo para recordar esta victoria en el que también se menciona el nombre de Cástulo y su ubicación junto al "río Rojo" o Guadalimar:

"Él hizo imborrable el día de Wādīl-Ahmar;
¡maldición para los (enemigos) muertos,
que quedaron en los vados
convertidos en carroña, y cuyos huesos
blanquean, insepultos
de noche, ofrecen a los lobos un festín,
y de día sirven para hartazgo de los buitres.
Les dio la muerte, una espada de filo
destructor,"
Allá en Cazlona, en Wadī l-Ahmar"
(HERNÁNDEZ GIMÉNEZ 1964: 6)

Desde luego Cástulo, aunque ya no debía ser una gran ciudad, mantenía la suficiente infraestructura como para albergar a los opositores del régimen omeya (CASTILLO ARMENTEROS Y GUTIÉRREZ CALDERÓN 2008: 86) y la arqueología avala, para este momento, la continuidad del poblamiento por la utilización de grandes edificios de la época imperial romana como las cisternas que sirvieron de vivienda. (SALVATIERRA CUENCA 2006: 61)

\footnotetext{
1 Sobre el poeta Abū l-Majšī, véase GALLEGA ORTEGA, T., (2012): “Abū l-Majš̄”, Biblioteca de al-Andalus, no 5, 1, Almería, pp. $48-50$.
} 
Las noticias sobre Cástulo volverán a aparecer a finales del emirato independiente, durante el reinado del emir 'Abd Allāh (888-912) con motivo de la gran rebelión muladí contra el Estado cordobés (SALVATIERRA CUENCA 2001). Los muladíes, es decir, la población cristiana autóctona convertida al Islam, serían acaudillados por el célebre rebelde 'Umar ibn Ḥafșūn desde la fortaleza malagueña de Bobastro. Uno de sus aliados en Jaén será 'Ubayd Allāh ibn al-Šāliya, emparentado con el líder muladí mediante el casamiento de una de sus hijas con uno de los hijos de Ibn Hafșūn, Ilamado Ŷa'far. Ibn al-Šāliya, que dispuso de su propia corte con sus poetas áulicos como 'Ubaydīs ibn Maḥmūd ${ }^{2}$, controlaba la zona giennense conocida como Ŷabal Šumuntān ${ }^{3} y$, entre las fortalezas de las que se había apoderado además, se cita la de Qastulūna.

La posesión de Qastulūna le había sido disputada a Ibn al-Šāliya por un grupo de cristianos pero la familia de los Banū Qasī, también aliada de 'Umar b. Hafsūn, acudió en su ayuda de modo que, en el año 898, Lubb ibn Qasī, saliendo de Toledo, asedió el Hișn Qastulūna y mató a los cristianos, que la retenían, conquistando la plaza (TERÉS 1976: 92; AGUIRRE SÁDABA y JIMÉNEZ MATA 1979: 158, n. 480).
El rebelde Ibn al-Šāliya no fue sometido por completo hasta el reinado de 'Abd al-Raḥmān III, quien le derrotó en 913, logrando, de este modo, controlar el centenar de fortalezas que le obedecían, y aunque el emir le llevó a Córdoba junto a él y le concedió rangos y honores, acabaría devolviéndole a Šumuntān, en calidad de gobernador de la zona hasta que la apaciguó y finalmente regresó a Córdoba (TERÉS 1976: 93).

Parece evidente que, para principios del siglo X, Qastulūna había dejado de ser una madina y se había convertido en un hișn o castillo refugio (ACIÉN ALMANSA 1999: 54) reaprovechando sus pobladores los restos de la fortificación romana, tanto de la muralla como de las torres, en el extremo norte del yacimiento (CASTILLO ARMENTEROS 1998: 290), un lugar donde aparecieron fragmentos cerámicos atribuibles al periodo islámico (CAMPOS LÓPEZ y PARRILLA SÁNCHEZ 2008: 62). Esta zona septentrional de Cástulo es idónea para el asentamiento por tratarse de una meseta natural que se eleva sobre el resto del conjunto y las más recientes excavaciones confirman allí una intensa actividad de refortificación durante el periodo emiral ${ }^{4}$.

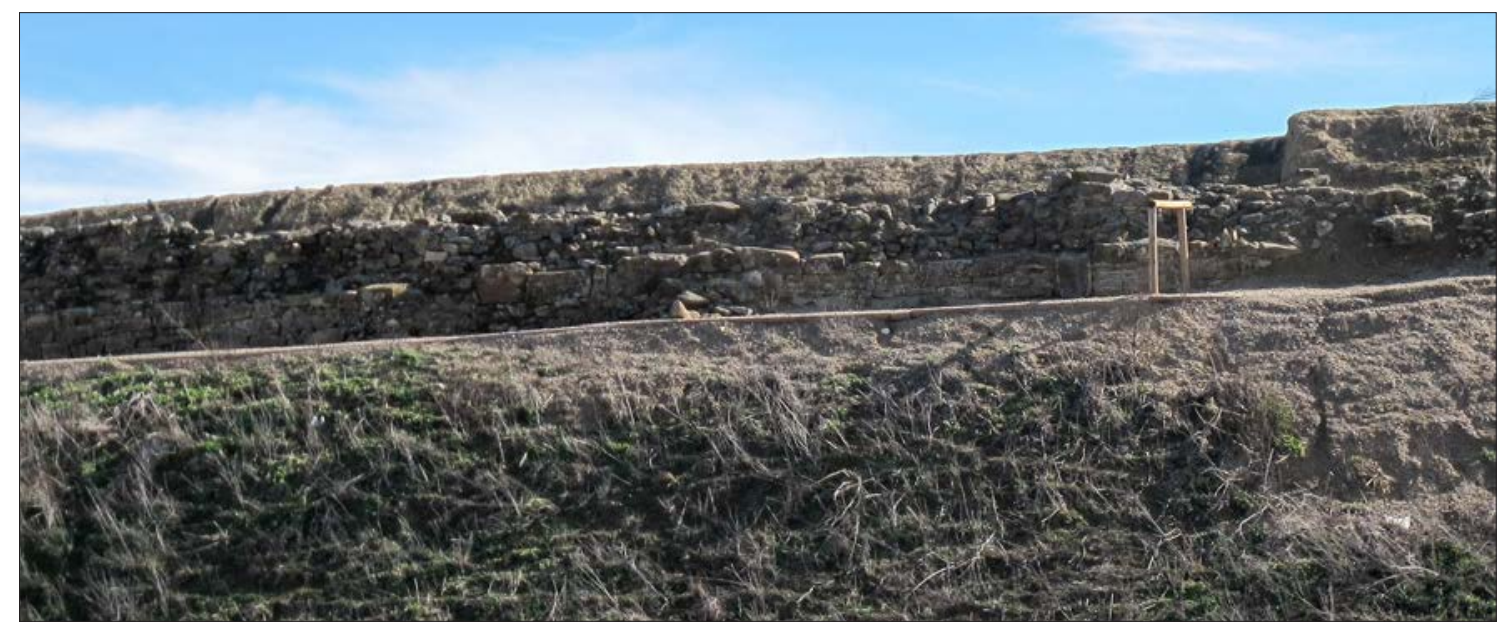

Fig. 1. Muralla Norte de Cástulo

\footnotetext{
2 Sobre el poeta "Ubaydīs ibn Mahmūd véase TERÉS, E., (1976): "Ubaydīs ibn Mahmūd y Lubb ibn al-Šaliya, poetas de Šumuntān (Jaén)", al-Andalus, XLI-I, pp. 87-120 y LIROLA DELGADO, J. (2006): “Ibn Maḥmūd al-Nafzī, “Ubaydīs”, Biblioteca de al-Andalus, no 750, 4, Almería, pp. 61-63.

3 Identificada anteriormente con Sierra Mágina, ŷabal Šummuntan parece que se corresponde con la Sierra de Segura, véase SALVATIERRA CUENCA, V. (2006): El Alto Guadalquivir en época islámica, Jaén, pp. 107-108.

4 Agradecemos estos datos aún inéditos en la bibliografía al profesor Vicente Salvatierra.
} 
En 920 'Abd al-Raḥmān III pasó por Majāḍat al-Fath camino de su campaña por Navarra. Pero ya no se volverá a mencionar el nombre de Qastulūna en las noticias históricas siendo probable que la fortaleza hubiera sido desmantelada por el futuro califa omeya para evitar posteriores conatos de rebeldía en la zona. (TORRES BALBÁS 1957: 121-122)

\section{NOTICIAS GEOGRÁFICAS SOBRE QASṬULŪNA}

En cambio, las noticias sobre Cástulo en las fuentes geográficas árabes son prácticamente inexistentes, así F. J. Aguirre y $\mathrm{M}^{\mathrm{a}}$ Carmen Jiménez en su clásica y conocida obra titulada Introducción al Jaén Islámico (AGUIRRE SÁDABA y JIMÉNEZ MATA 1979: 42) lo reconocían indicando que los geógrafos árabes, que describen la cora o provincia de Yayyān (Jaén), omiten en su mayoría referencias a Cástulo y que esto era una señal inequívoca de la pérdida de prestigio de la ciudad durante la época musulmana. Así por ejemplo, el geógrafo al-Bakrī ${ }^{5}$ en el siglo XI sólo menciona a Cástulo para nombrarla dentro de una relación de veinte ciudades pertenecientes a la zona cuarta peninsular, es decir, al centro-este de la Península. En esa relación, Cástulo figura entre las ciudades de Baeza y Mentesa pero el traductor la identifica erróneamente en sus notas con Segura de la Sierra (AL-BAKRĪ, 1982: 17, n. 19)

Esta falta de noticias es un hecho indudable al que hay que unir otro problema que dificulta la visibilidad de Cástulo en las fuentes geográficas árabes: la nomenclatura tan variada con la que aparece el topónimo en los tratados de Geografía y en la bibliografía como vamos a ver.
Quizás el Mưŷym al-buldān de Yāqūt ${ }^{6}$ se refiera a Cástulo cuando menciona la ciudad de Qasțurra, de la que dice que es una ciudad dependiente del 'amāl de Jaén, situada entre Jaén y Baeza. El traductor de esta obra se preguntaba si podía tratarse de Cazorla por el parecido del nombre, aunque, por la situación que menciona, entre Jaén y Baeza, Cástulo se adecúe mejor que Cazorla cuya situación es más oriental (YĀQŪT, 1974: 276, n. 87).

Por último, hay que señalar que Cástulo ha sido identificado también en la bibliografía con el topónimo Nantaska (VALLVÉ BERMEJO 1986: 65 y SALVATIERRA CUENCA 2008: 146) Sin embargo, esta identificación no es segura teniendo en cuenta que el geógrafo granadino del siglo XII Ibn Gālib ${ }^{7}$, indica que Nantaska era un lugar que exportaba madera a todo al-Andalus (VALLVÉ BERMEJO 1975: 373), referencia que parece aludir a algún enclave en la Sierra de Segura, famosa por la exportación de madera de pino desde la Edad Media, un lugar quizás como Tíscar, cuyo nombre fácilmente podría derivar de este topónimo de Nantaska.

Sin embargo, en este artículo queremos dar a conocer lo que dice el resto de geógrafos árabes sobre Cástulo, aunque esta información sea escasa, porque puede tener importancia para la interpretación de un territorio en la Alta Edad Media como es el valle del río Guadalimar.

Es el geógrafo persa del siglo XIII, al-Qazwī$n \bar{~}{ }^{8}$ quien ofrece una curiosa noticia sobre Cástulo. Hacia el año 1275 compuso una obra denominada Ātār al-bilād wa ajbār al-'lbād que podría traducirse como "Vestigios de los países y noticias de los siervos de Dios", en la que compendió sus conocimientos geográficos sobre el mundo. Al-Qazwīnī dividió la Tie-

5 Sobre al-Bakrī, uno de los geógrafos más importantes de al-Andalus, fallecido en 1094, véase LIROLA DELGADO, Jorge (2012): "al-Bakrī, Abū 'Ubayd". Biblioteca de al-Andalus, no 51, 1, Almería, pp. 154-160.

6 Sobre el esclavo manumitido Yãqūt, de origen bizantino, nacido en 1179 y fallecido en 1229, véase YĀQŪT (1974): Mu'ŷam al-buldān, trad. parcial de 'ABD AL-KARĪM, Gamāl, "La España musulmana en la obra de Yāqūt (s. XII-XIII). Repertorio enciclopédico de ciudades, castillos y lugares de al-Andalus, extraído del Mu'ŷam al-buldān (Diccionario de los países)", Cuadernos de Historia del Islam, 6, pp. 25-29.

7 Sobre Ibn Gālib véase GARCíA SANJUÁN, A. (2004), "Ibn Gālib al-Anșārī, Muḥammad”, Biblioteca de al-Andalus, no 494, 3, Almería, pp. 199-201.

8 Geógrafo persa nacido en 1203 y fallecido en 1283. Sobre al-Qazwīnī véase ROLDÁN CASTRO, F. (1990): El Occidente de al-Andalus en el Ātāar al-bilād de al-Qazwīiñ, Sevilla, 17-19. 
rra en siete climas y la parte correspondiente a al-Andalus ha sido parcialmente traducida por la profesora de la universidad de Sevilla, Fátima Roldán Castro; en 1990 apareció su obra El Occidente de al-Andalus en la que no se presentaban los topónimos de la cora de Jaén por circunscribirse sólo a la zona occidental. Sin embargo, en 1992, la misma autora publicó la traducción correspondiente a la zona oriental (ROLDÁN CASTRO 1992) y aunque esta vez sí aparecían referencias a la provincia giennense, la autora omitía la traducción del pequeño pasaje dedicado a Qasțulūna, quizás por ser una ciudad desaparecida, de modo que no conociendo otra traducción sobre el mismo la ofrecemos ahora:

\section{"Qasțulūna (Cástulo):}

Es una ciudad antigua en al-Andalus cerca de Basța (Baza). En ella hay una montaña que tiene una cueva por donde se filtra el agua desde el techo, en una pequeña cavidad que hay debajo, gota a gota. El agua se acumula en esa cavidad por causa del filtrado y no disminuye, y aunque se beba agua de esa oquedad muchas veces, no disminuye.

Dijo al-'Udrī: Me informó de ese fenómeno un grupo de gente que lo presenció y este caso es público y notorio en ese lugary añadió: en esa cueva hay un cadáver que permanece incorrupto a lo largo del tiempo pero no conozco su historia." (AL-QAZWĪNĪ, 1984: 553).

Por desgracia, la fuente que menciona al-Qazwīnī, la obra geográfica de al-'Ud dīī ${ }^{9}$, ha llegado a nuestros días muy fragmentada y no podemos confirmar esta noticia que al-Qazwinì dice tomar de él porque no se conserva el texto sobre la cora de Jaén. Si aparecieran las noticias que al-'Udrī escribió al respecto sería sumamente interesante puesto que este geógrafo era andalusí, concretamente de Almería, y estaba más próximo en el tiempo al periodo en el que Cástulo aún acogía numerosa población. Al-‘Udrī vivió en el siglo XI, dándose la circunstancia de referir un testimonio oral porque fue informado por "un grupo de gente que lo presenció".

Posteriormente, en el siglo XIV, el geógrafo al-Himyarī ${ }^{10}$ recopila esta información de al-Qazwīnī en su Rawd al-mi'tār fĩ jabar al-aqțār "Libro del jardín perfumado acerca de las noticias de las regiones" aunque, en este diccionario geográfico, el nombre de Cástulo se halla tergiversado también, pues aparece como Qarnāta (AL-HIMYARĪ, 1975: 461). Lévi-Provençal (AL-HIIMYARĪ, 1938: 191, n. 2), en la traducción francesa que hizo de esta fuente, ya se dio cuenta de que, aunque no podía identificar este topónimo de Qarnāța, la noticia que proporcionaba al-Himyarī era idéntica a la que consignaba al-Qazwīnī para Qastulūna. En la traducción española, que Pilar Maestro hizo del Rawḍ al-mi'țār de al-Himyarī, podemos leer:

\section{"Karnāta}

Ciudad de al-Andalus, en una región alejada de los centros habitados. En unas montañas elevadas de esta región hay una caverna que encierra un cadáver de un hombre que permanece intacto a pesar del paso del tiempo, y se ignora de qué época es. Desde lo alto de esta caverna gotea el agua en una pequeña oquedad de la roca; el agua, que cae continuamente, no se desborda nunca; y además, si alguna persona o muchas, incluso numerosas, van a alli a beber, el agua no baja.

Se cuenta que cierto bromista de mal gusto levantó parte del vestido funerario de este muerto: fue fulminado al instante." (AL-HIMYARĪ, 1963: 322)

Lo primero que podríamos reseñar de ambos textos es la coincidencia en su contenido y en la ubicación del lugar: una cueva de relieve kárstico donde el agua se filtra desde el techo y se acumula en una oquedad sin

\footnotetext{
9 Sobre el geógrafo al-'Udrī (1003-1085) que sentía un especial interés por la literatura de 'aŷāÿib, véase LIROLA DELGADO, J. (2012): "al-'Uḍrī, Abū l-'Abbās", Biblioteca de al-Andalus, no 1808, 7, Almería, pp. 559-570.

10 Sobre al-H.imyarī, erudito de origen ceutí o tunecino fallecido en la primera mitad del siglo XIV, véase NAVARRO OLTRA, V.C., "al-Ḥimyarī, Abū 'Ábd Allāh ibn al-Mun'im”, Biblioteca de al-Andalus, no 152, 1, Almería, pp. 444-451.
} 
agotarse aunque se beba de ella y la existencia de un misterioso cuerpo incorrupto en su interior. En segundo lugar, hay que destacar que al-Qazwīni se equivoca al mencionar que Cástulo se halla próximo a Baza. Como ya señaló en su día el profesor Joaquín Vallvé (VALLVÉ BERMEJO 1969: 64), la grafía de ese topónimo no es correcta y evidentemente al-Qazwīnī debía referirse a Bayyasa (Baeza) y no Basta porque su proximidad a Cástulo es notoria, sólo 15 km., mientras que Baza en la provincia de Granada se encuentra ya a $100 \mathrm{~km}$. De cualquier modo, tenemos que reconocer que es un error comprensible para alguien como al-Qazwīnī que escribe su obra geográfica desde la lejana Persia, aunque esté citando a al-'Udrī. Por último, reseñar que la extraña grafía proporcionada por al-Himyarī para el lugar donde se encontraba esa cueva, ha hecho que no haya sido ubicada, así en la única traducción española de la obra, ese extraño Karnāta no se identifica con ningún lugar concreto de al-Andalus.

En cuanto al tipo de relato presentado por al-Qazwīnī y al-Himyarī, habría que decir que se trata de un exponente característico de un género conocido en las fuentes árabes como 'Aŷa'ib ${ }^{11}$ o "hechos maravillosos y sorprendentes" que tanto abundan en los tratados de geografía. Obviando los poderes taumatúrgicos del cadáver, la alusión a la ubicación del mismo custodiado en una cueva, puede ser interpretada como una referencia concreta a algún santuario rupestre mozárabe que hubiera en Cástulo o en sus inmediaciones.

En el Islam se alude con frecuencia a leyendas relacionadas con cuerpos incorruptos que son objeto de veneración por parte de los rumíes o cristianos, como la famosa leyenda de los 7 durmientes de Éfeso (HERNÁNDEZ JUBERÍAS, 1996: 121-137). Fue ésta una leyenda de gran trascendencia en el mundo islámico porque es recogida en el Corán, precisamente en la sura llamada de la Caverna:
"No te has parado a pensar que los compañeros de la Caverna y al-Raqim fueron parte de los signos sorprendentes de tu Señor?

Cuando los jóvenes se refugiaron en la caverna dijeron:

iSeñor nuestro, concédenos una misericordia de Tu partey resuelve nuestra situación dándonos una dirección correcta!

Y los dejamos dormidos dentro de la caverna durante un determinado número de años" (CORÁN, 1998: 18, 9-11)

Más adelante, en la misma sura se indica que el número de aquellos jóvenes sería objeto de controversia (CORÁN 1998: 18, 22) y que fueron 309 años los que estuvieron dormidos (CORÁN 1998: 18, 25).

En la tradición islámica, los durmientes santos esperan la resurrección y el estado extraordinario de sus cuerpos sólo puede responder a un mandato divino por lo que despiertan la admiración y veneración de los fieles que acaban formando una comunidad en torno a ellos. En las fuentes geográficas árabes, dada la enorme difusión que tuvo la leyenda de los 7 durmientes, se mencionan con frecuencia este tipo de cuevas que albergan cuerpos de santos (șulahāa'). Las cuevas en cuestión son localizadas por todo Oriente, en Anatolia, en Jordania, pero también se da la circunstancia de documentarse en Occidente.

Así, en al-Andalus, fue famosa la cueva de Loja que, al igual que la caverna de Éfeso, guardaba siete cuerpos incorruptos (HERNÁNDEZ JUBERÍAS, 1996: 150-161). El geógrafo al-'Udrī es el primero en hablar de la existencia de esta cueva en Loja (HERNÁNDEZ JUBERÍAS, 1996: 151) y al-Zuhrī ${ }^{12}$ menciona datos tan significativos como que hubiera un oratorio sobre la misma, reconstruido por el șāhib al-šurta de la ciudad en 1137 que, además,

11 Sobre los “aŷāÿib, término que puede traducirse como "las maravillas de la creación”, véase HERNÁNDEZ JUBERÍAS, J. (1996): La Península imaginaria. Mitos y leyendas sobre al-Andalus, Madrid, pp. 249-255.

12 Sobre al-Zuhrī, geógrafo del siglo XII de probable origen almeriense, véase BRAMÓN, D., (2012), "Al-Zuhrī, Abū 'Abd Allāh", Biblioteca de al-Andalus, no 1892, 7, Almería, pp. 742-745. 
mandó orientar correctamente su mihrāb (HERNÁNDEZ JUBERÍAS, 1996: 153). Por lo que sabemos, el culto a estos cuerpos santos implicaba que la gente se preocupara de cambiarles las vestiduras regularmente y que fueran a hacerles rogativas que se esperaba que los durmientes cumplieran.

\section{EREMITORIOS ALTOMEDIEVALES EN EL VALLE DEL GUADALIMAR}

En la ciudad de Cástulo se han encontrado diversas necrópolis no sólo ibéricas y romanas sino también altomedievales como una necrópolis visigoda del segundo cuarto del siglo VII (BLÁZQUEZ MARTÍNEZ y GARCÍA-GELABERT 1999: 24) dentro de una basílica decorada con pinturas (GARCÍA-GELABERT y BLÁZQUEZ MARTíNEZ 1994: 338). La noticia de al-Qazwīnī nos lleva a pensar que existió además en Cástulo para esa época un santuario y/o eremitorio rupestre creado en torno al culto de algún santo o, al menos, si no en el mismo Cástulo, sí en la zona de influencia de la ciudad, en cuyo caso tendríamos que admitir la posibilidad de que el texto de al-Qazwīnī estuviera aludiendo a alguno de los diversos eremitorios altomedievales que existen en las inmediaciones de Cástulo en el valle del río Guadalimar. Con respecto a los mismos, sabemos que había por lo menos tres eremitorios cercanos a Cástulo: dos en el término de Rus, los de Valdecanales, a 17 kilómetros, y la Veguilla, a 14 kilómetros, (VAÑO SILVESTRE, 1970 y CASAS GARRIDO, 2000); y uno en el término de Vilches, el de Giribaile, a unos 14 kilómetros de distancia también (Gutiérrez Soler, 2011: 38-39).

El cenobio de Giribaile está compuesto por cuatro complejos rupestres en los que se incluyen un oratorio, una iglesia y una necrópolis excavada en la roca. El poblamiento rupestre de Giribaile ha sido relacionado con una ocupación tardo-romana y visigoda que continuó en el valle del Guadalimar hasta el periodo emiral con los mozárabes (Gutiérrez Soler 2011: 253). En sus cuevas se hallan inci-

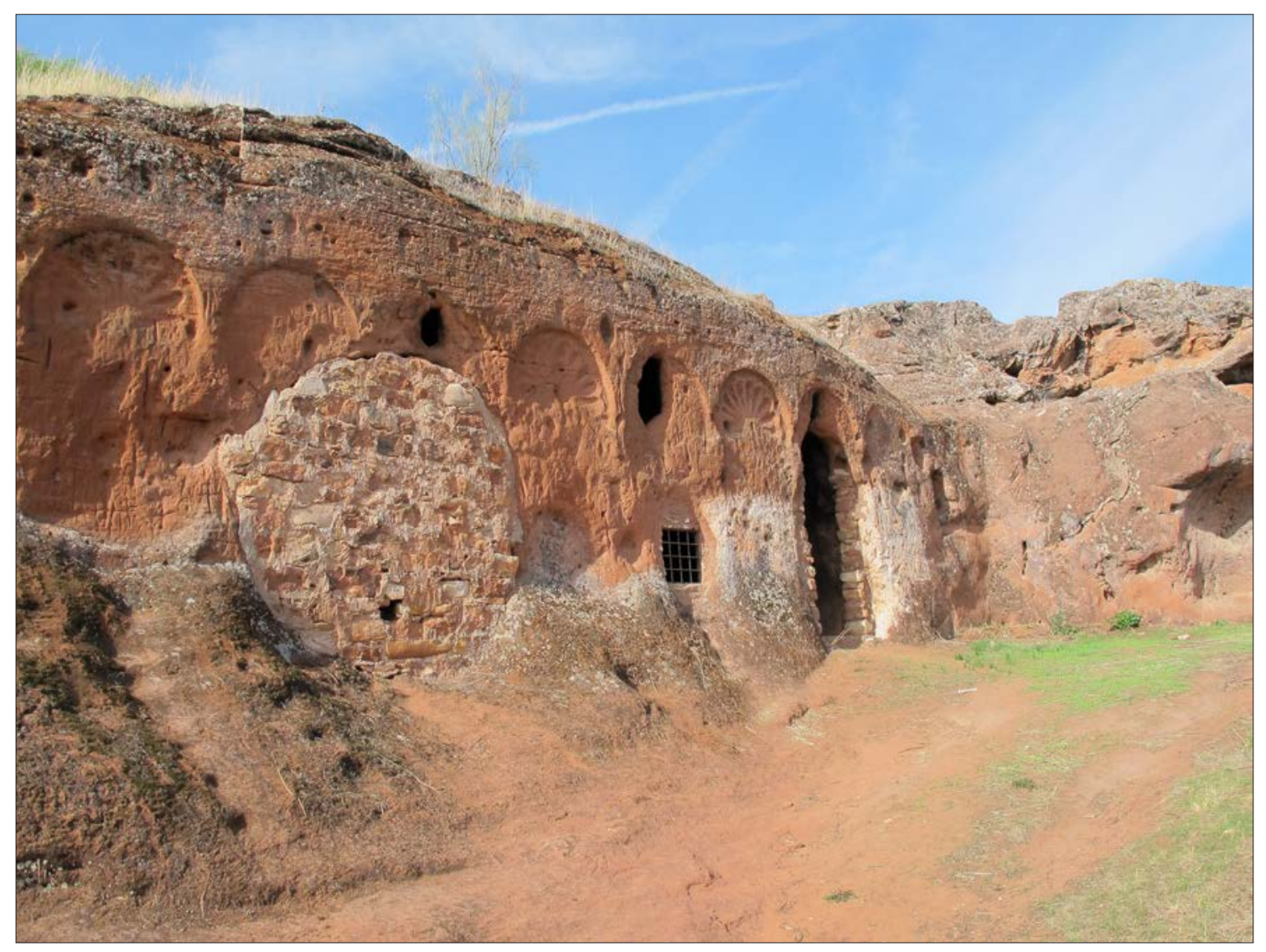

Fig. 2. Oratorio de Valdecanales 


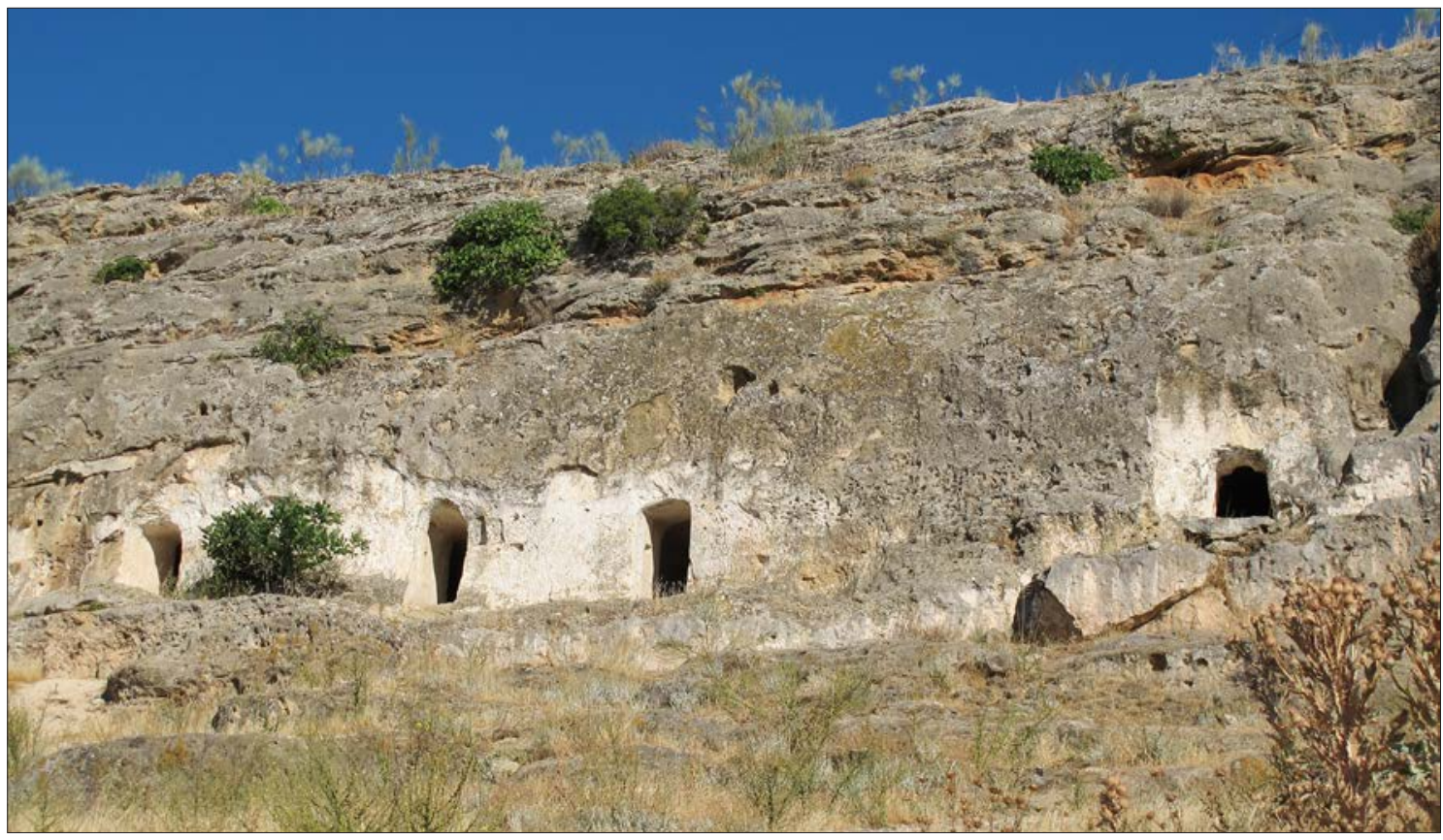

Fig. 3. Eremitorio de Giribaile (Vilches).

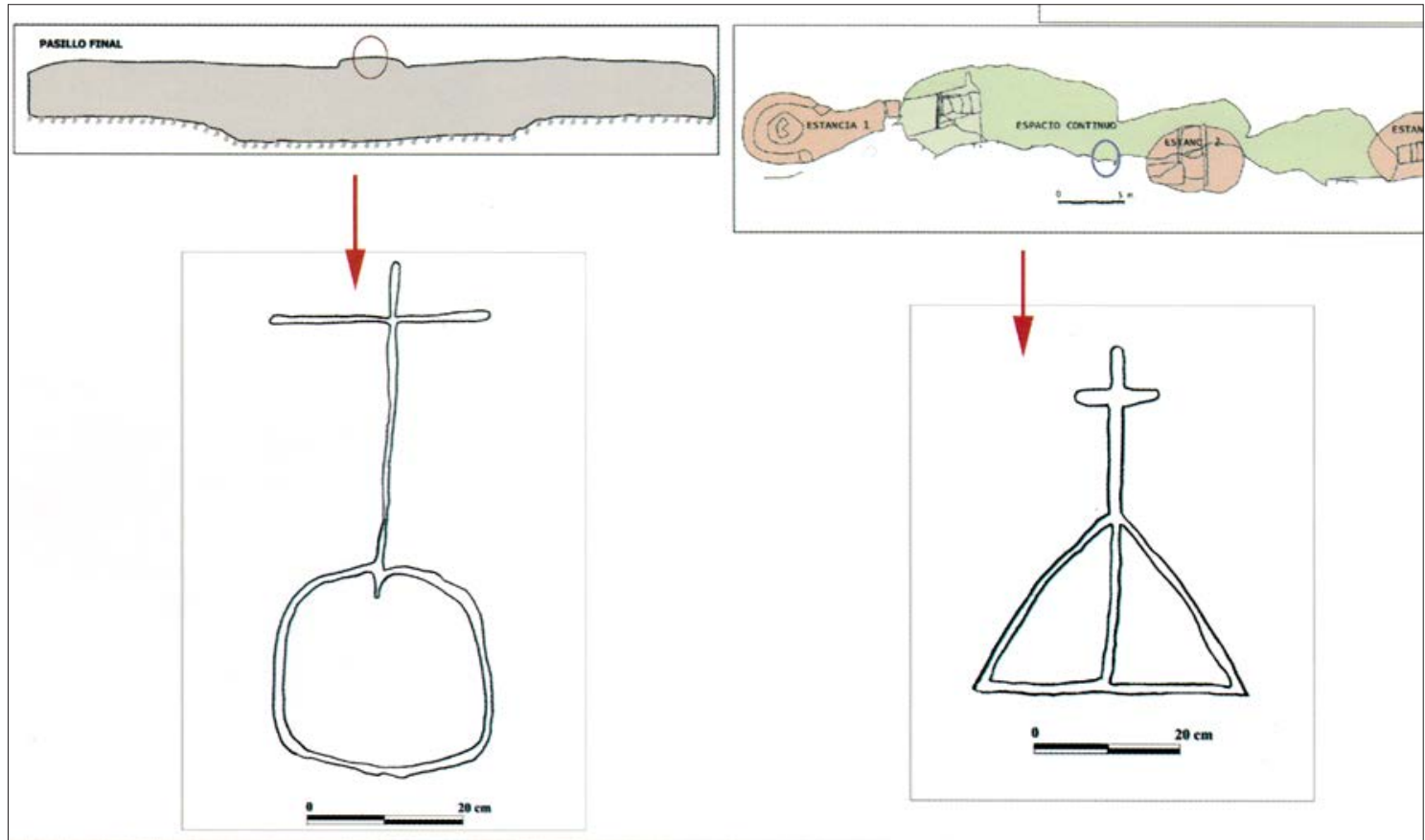

Fig. 4. Cruces de Giribaile (Gutiérrez Soler 2011: 298)

sos símbolos cruciformes como la cruz latina sobre peana triangular o la cruz griega inscrita en un círculo, símbolos interpretados no como representaciones de antropomorfos prehistóricos sino como manifestaciones religiosas cristianas (Gutiérrez Soler 2011: 312).
Todos estos eremitorios conforman un poblamiento rupestre de cierta entidad que ha comenzado a definirse (Gutiérrez Soler, 2011: 253) en el marco del fenómeno de utilización de las cuevas en Andalucía oriental, junto con otras manifestaciones en la provincia de 
Jaén como el cenobio visigótico-mozárabe del Tajo de la Muela en Cambil (ESCOBEDO MOLINOS 2008).

También en la zona de influencia de Giribaile se ha documentado arqueológicamente la ocupación de la tierra en época tardoromana y/o visigoda (Gutiérrez Soler 2011: 315) y es probable, como indica Gutiérrez Soler, que dicha ocupación esté relacionada con el auge del movimiento eremítico y monástico que experimentó Andalucía desde mediados del siglo VII y que continuó en época mozárabe (CASTILLO 2006: 128-129). Precisamente, la fundación del monasterio de Valdecanales ha sido puesta en relación con las reglas de san Isidoro y san Fructuoso que, a mediados del siglo VII, fomentaban la construcción de monasterios en lugares alejados y solitarios (GARCÍA MORENO 2007: 458, n. 128)

Además, hay que tener en cuenta que Cástulo fue un centro cristiano muy importante desde la Antigüedad, en la ciudad se ha encontrado recientemente una extraordinaria patena paleocristiana de vidrio con una imagen muy primitiva de Cristo, imberbe y con el cabello rizado al estilo alejandrino, datable en la $2^{a}$ mitad del siglo IV d. C. Así mismo, es de sobra conocido que Cástulo albergó su propia sede episcopal hasta que, entre los años 656 y 675, por motivos desconocidos, la cátedra de Cástulo se trasladó a Baeza en época del rey visigodo Recesvinto (CONTRERAS DE LA PAZ, 1959: 110). El obispo Marcos de Cástulo había asistido al VIII concilio de Toledo celebrado en el año 653, al IX del 655 y al X del 656 pues firmó sus actas, pero en el XI concilio de Toledo, celebrado en 675 durante el reinado de Wamba, ya no firmó ningún obispo de Cástulo y sí lo hizo, por primera vez, un obispo de Baeza, Regato (FLÓREZ 1766: VII, 152; TORRES BALBÁS 1957: 119). La desaparición de la sede episcopal castulonense se ha relacionado con un abandono de la ciudad por parte de sus habitantes, y como causa del mismo se ha hipotetizado con la persistencia de las plagas de langosta en la zona como un mal endémico que arruinaría la economía de Cástulo (GARCÍA MORENO 2007: 458).

La importancia religiosa de Cástulo como sede episcopal en el bajo imperio y la Alta Edad Media quedará reflejada en la historiografía eclesiástica de la Edad Moderna (LÓPEZ PINTO s.d; RUS PUERTA 1634; BILCHES 1653; XIMENA JURADO 1654; FLÓREZ 1766) y aunque todo ello no dejara de ser un intento de sacralizar la historia por parte de la Iglesia de la Contrarreforma (CHOCLÁN SABINA 2008: 32), tampoco sería de extrañar que hubiera existido dentro de Cástulo o en sus inmediaciones por lo menos algún santuario, tal vez consagrado a algún santo incorrupto relevante para la ciudad. Una fuente de escaso crédito, que menciona posibles candidatos para poner una advocación a este hipotético santuario, es el padre Bilches, que recoge en su obra el

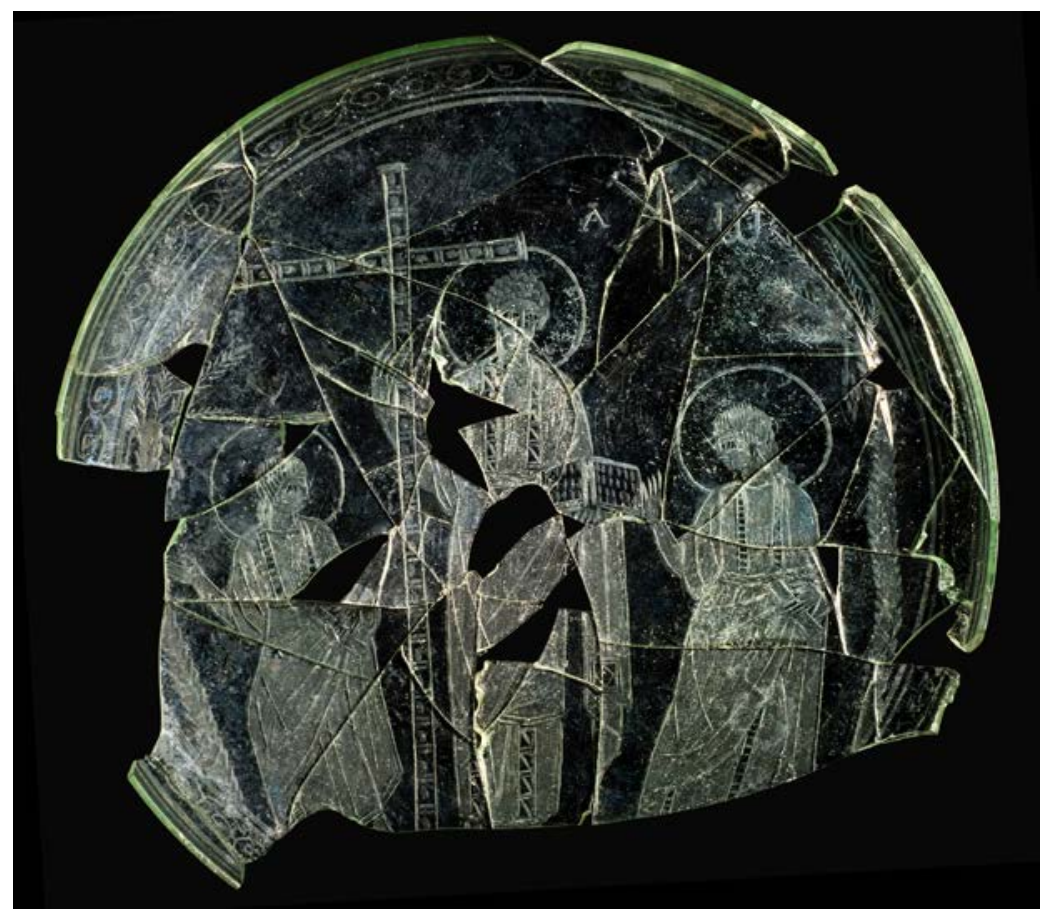

Fig. 5. Representación de la Patena de Cástulo. Folleto informativo del Museo Arqueológico de Linares. 
nombre de varios mártires de Cástulo como san Marco, san Hadria y san Faustino (BILCHES 1653:19-20). Este jesuita también menciona a san Secundino, obispo de Cástulo que estuvo en el concilio de llíberis, a comienzos del siglo IV, y que, supuestamente, era el mismo que cierto mártir homónimo que falleció en Córdoba en el año 305 (BILCHES 1653: 56-58). También menciona a san Amando como obispo de Cástulo (BILCHES 1653:73-78; PADILLA CERÓN 2011: 241) aunque ese error fuera aclarado posteriormente (FLÓREZ 1766: VII, 151-157) porque san Amando fue, en realidad, obispo de Utrech y no de Cástulo.

Entre los hagiotopónimos de la zona no encontramos ninguna advocación válida para el supuesto santuario pues tenemos los de san Ambrosio y santa Eufemia. El primero da nombre a un arroyo que discurre por la parte occidental de Cástulo y desagua en el Guadalimar. Pero san Ambrosio no fue un santo hispánico pues fue obispo de Milán y está enterrado en la basílica que lleva su nombre.

Con respecto a Santa Eufemia, sabemos que en la zona había una ermita dedicada a esta santa (PADILLA CERÓN 2011: 239-244; SÁNCHEZ LÓPEZ; INFANTE LIMÓN y VALIENTE ROMERO 2012) porque el padre jesuita Jerónimo Román de la Higuera, fallecido en 1611, atribuyó a Cástulo la ubicación del martirio de santa Eufemia, aunque dicha santa falleció, en realidad, en Calcedonia en el año 138. Sin embargo, el obispo de Jaén, Moscoso y Sandoval (1619-1646), dio pábulo a las historias de Román de la Higuera y, en consecuencia, los habitantes de la zona creyeron dicha atribución y edificaron una ermita en honor a la santa (CORTÉS Y LÓPEZ 1836: 333). En la actualidad santa Eufemia le da nombre al Torreón almohade de Cástulo (V.AA. 2002) porque la ermita estaba situada en sus proximidades.

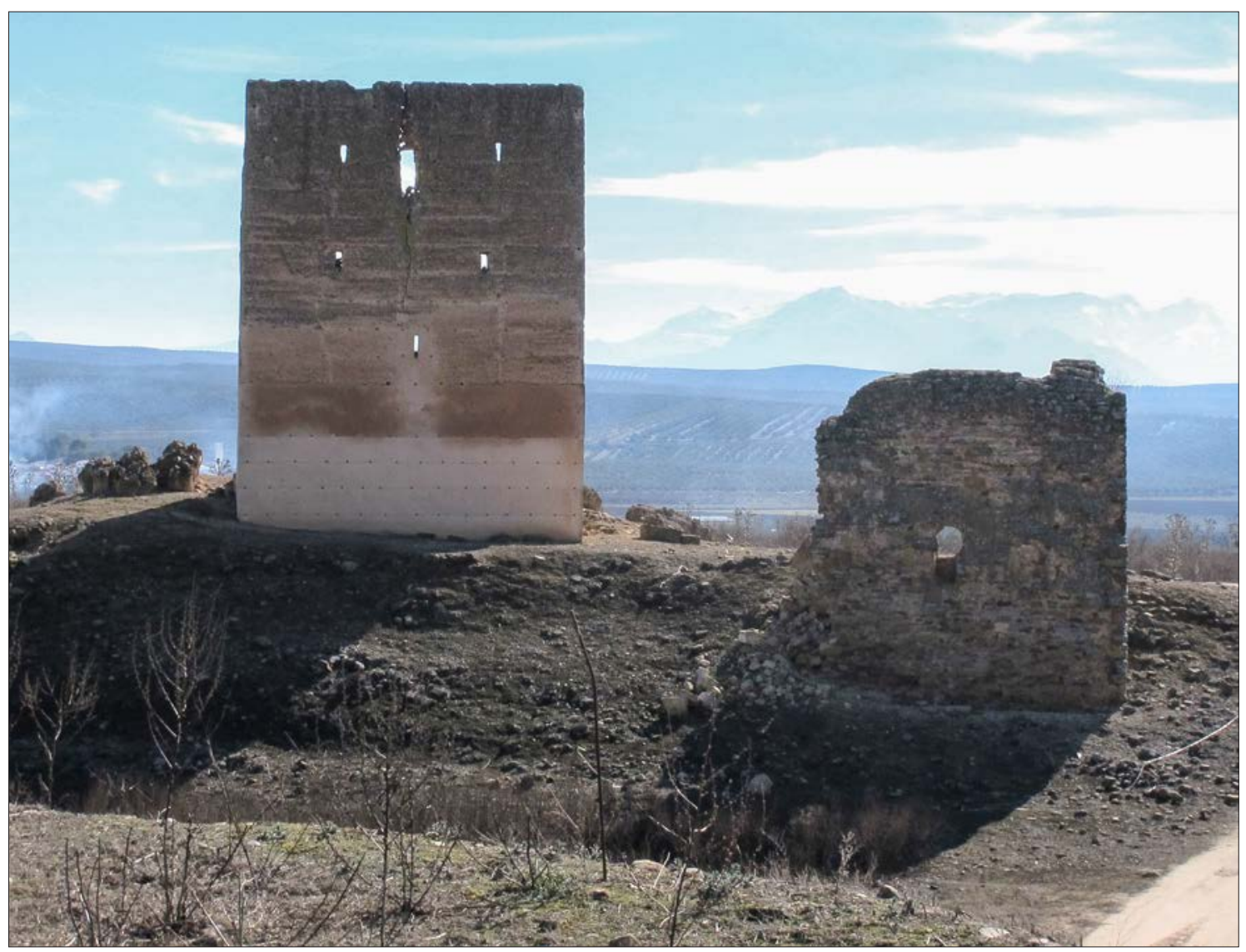

Fig. 6. Castillo de Santa Eufemia en Cástulo. 


\section{CONCLUSIONES}

La importancia de Cástulo como centro cristiano de prestigio en la Alta Edad Media viene avalada por la existencia de una sede episcopal y de un santuario rupestre, con un probable eremitorio asociado, cuyos restos llegaron hasta el siglo XI, por lo menos, según el testimonio del geógrafo almeriense al-'Udrī cuyas noticias, aunque perdidas, nos han llegado a través de la obra del persa al-Qazwīnī.

La ubicación exacta de ese santuario rupestre se nos escapa, pudiendo estar localizado en alguna cueva de la propia ciudad romana o en algunos de los eremitorios próximos a Cástulo como el de Valdecanales, la Veguilla o el de Giribaile. Quizás, por la importancia del cuerpo santo que albergaba, capaz de obrar prodigios ante un irreverente musulmán, pudiera tratarse del de Valdecanales, dado el refinamiento artístico de su fachada, lo cual podría deberse al hecho de acoger el culto de un santo popular en la zona.
Por otro lado, la veneración de cuerpos incorruptos como los 7 durmientes de Éfeso fue conocida en Europa Occidental; el introductor del culto a los mismos fue Gregorio de Tours en la segunda mitad del siglo VI, y en la Península su culto también está atestiguado por san Isidoro de Sevilla, quien señaló el 27 de julio como el día de la celebración de su festividad en su calendario eclesiástico, referencia obligada para los mozárabes posteriores (HERNÁNDEZ JUBERÍAS 1996: 160). Incluso no ha faltado algún autor que asegurara que en la propia mezquita de Córdoba había una representación figurativa, esculpida o pintada, de los 7 durmientes de Éfeso (FERRANDIS 1935: 24, n. 2). De manera que la veneración en la zona de Cástulo de un representante local del culto a santos incorruptos, como los 7 durmientes de Éfeso, en época visigoda o por lo menos desde los tiempos de san Isidoro de Sevilla, no resultaría tan extraño para las comunidades altomedievales cristianas que sostuvieron los eremitorios rupestres del valle del Guadalimar.

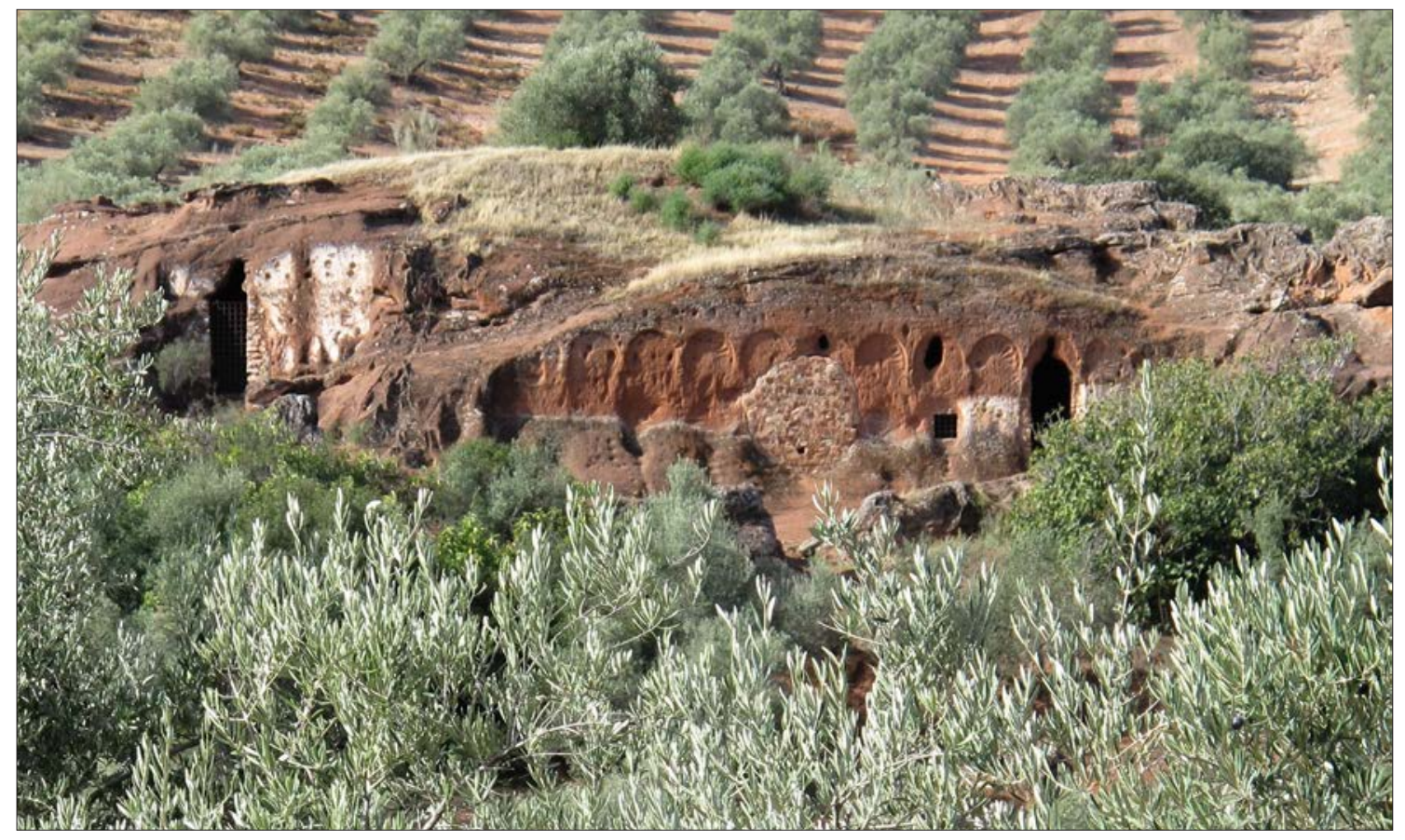

Fig. 7. Conjunto rupestre de Valdecanales 


\section{FUENTES}

AJBĀR MAŶMU'A (1867), trad. Emilio Lafuente y Alcántara, Madrid.

Al-BAKRT̄ (1982): Kitāb al-masālik wa l-mamālik, Geografía de España, trad. E. Vidal Beltrán, Zaragoza.

CORÁN (1998): trad. Abdel Ghany Melara Navío, Palma de Mallorca.

AL-ḤIMYARĪ (1938): Rawd al-mi'tār fĩ jabar al-aqțār, La Péninsule Ibérique au Moyen-Âge d'après le kitāb ar-Rawd al-mi'tār fī Habar al-aktāar d'lbn 'Abd Allāh al-Himyarī, ed. y trad. Lévi-Provençal, Leiden, E.J. Brill.

AL-HIMYARĪ (1963): Rawd al-mi'tār, trad. Pilar Maestro González, Anubar, Zaragoza.

AL-HIMYARI (1975): Rawḍ al-mi'țār fī jabar al-aqțār, ed. I. 'Ábbās, Beirut.

AL-QAZWĪNī (1984): Ātāàr al-bilād wa ajbār al-'ibād, Beirut.

YĀQŪT (1974): Mu'ŷam al-buldān, trad. parcial de 'ABD AL-KARĪM, Gamāl, "La España musulmana en la obra de Yāqūt (s. XII-XIII). Repertorio enciclopédico de ciudades, castillos y lugares de al-Andalus, extraído del Mu'ŷam al-buldān (Diccionario de los países)", Cuadernos de Historia del Islam, 6.

\section{BIBLIOGRAFÍA}

ACIÉN ALMANSA, Manuel (1989): "Poblamiento y fortificación en el sur de al-Andalus. La formación de un país de Husūn", III Congreso de Arqueología Medieval Española, Oviedo, pp. 137-150.

ACIÉN ALMANSA, Manuel (1999): "Poblamiento indígena en al-Andalus e indicios del primer poblamiento andalusí", al-Qanțara, XX-1, pp. 47-64.

AGUIRRE SÁDABA Francisco Javier y JIMÉNEZ MATA, Ma del Carmen (1979): Introducción al Jaén Islámico, Jaén.

BILCHES, Francisco de (1653): Santos y santuarios del obispado de Jaén y Baeza, Jaén.

BRAMON, Dolors (2012): "Al-Zuhrī, Abū 'Abd Allāh", Biblioteca de al-Andalus, no 1892, 7, Almería, pp. 742-745.

BLÁZQUEZ, J. M. y GARCÍA-GELABERT, M. P. (1999): Cástulo, Jaén, España. II. El conjunto arquitectónico del Olivar. En BAR International Series 789, Oxford.

CAMPOS LÓPEZ, Daniel y PARRILLA SÁNCHEZ, Juan, (2012): "Intervención arqueológica en el lienzo noreste de la muralla de Cástulo", I Congreso de Historia de Linares, abril 2008, Jaén, pp. 49-63.

CASAS GARRIDO, Camelia (2000): "Dos oratorios rupestres en la Loma: Valdecanales y la Veguilla (Rus, Jaén). En Colegio Oficial de Arquitectos de Jaén (ed.): Visitas al Patrimonio Histórico Provincial de Jaén 94/99, Jaén, pp. 154-158.
CASTILLO, P. (2006): La época visigótica en Jaén, Jaén.

CASTILLO ARMENTEROS, Juan Carlos (1997): “Cástulo, de Ciuitas a hisn”, Jaén, pueblos y ciudades, tomo V, Jaén, pp. 1693-1700.

CASTILLO ARMENTEROS, Juan Carlos (1998): La campiña de Jaén en época emiral (s. VIII-X), Jaén.

CASTILLO ARMENTEROS, Juan Carlos y GUTIÉRREZ CALDERÓN, Ma Victoria (2012): "Los años enigmáticos: la aldea de Linares desde sus orígenes hasta la independencia de Baeza (1565)", I Congreso de Historia de Linares, abril 2008, Jaén, pp. 75-107.

CHOCLÁN SABINA, Concepción (2012): "Cástulo: radiografía de un territorio", I Congreso de Historia de Linares, abril 2008, Jaén, pp. 29-47.

CONTRERAS DE LA PAZ, Rafael (1959): "Historia eclesiástica de Cástulo", Boletín del Instituto de Estudios Giennenses 20, pp. 97-120.

CONTRERAS DE LA PAZ, Rafael (1967): "Cástulo (Qastuluna) bajo la dominación musulmana", Oretania, nºs 25-27, pp. 5-23.

CORTÉS Y LÓPEZ, Miguel (1836): Diccionario geográficohistórico de la España Antigua Tarraconense, Bética y Lusitana, II, Madrid.

DÍAZ GARCÍA, Ma José, RUEDA GALÁN, Carmen, GUTIÉRREZ SOLER, Luis María, BEATRIZ LUNA, Mercedes, (2005): "Las Cuevas de Giribaile: Nuevas aportaciones para el Estudio del Poblamiento Eremítico en Andalucía Oriental", Arqueología y Territorio Medieval no 12, pp. 7-38.

ESCOBEDO MOLINOS, Enrique (2008): "Un eremitorio rupestre en Sierra Mágina”, Sumuntán, n²6, pp. 95-117.

FERRANDIS, José (1935): Marfiles árabes de Occidente, I, Madrid.

FLÓREZ, Enrique (1766): España Sagrada, VII, Madrid.

GALLEGA ORTEGA, Teófilo (2012): "Abū l-Majš̄”, Biblioteca de al-Andalus, I, n 5, Almería, pp. 48-50.

GARCíA-GELABERT, M. P y BLÁZQUEZ, J. M. (1994):"La importancia de Cástulo (Linares) en la Alta Andalucía. En Actas del Il Congreso de Historia de Andalucía. Córdoba, 1991, Córdoba, pp. 331-343.

GARCÍA MORENO, Luis A. (2007): "Transformaciones de la Bética durante la tardoantigüedad”, Mainake, XXIX, pp. 433-471.

GARCÍA SANJUÁN, A. (2004), "Ibn Gālib al-Ansārī, Muhammad", Biblioteca de al-Andalus, no 494, 3, Almería, pp. 199-201.

GÓNGORA Y MARTíNEZ, Manuel de (1915-1916 [1860]): "Viaje literario por las provincias de Jaén y Granada", Don Lope de Sosa, no 28, pp. 117-120; no 30, pp. 175-178; n 31, pp. 211-214; no 32, pp. 247-250; no 33, pp. 276-279; no 35, pp. 343-345; no 41, p. 148; no 43, p. 216 y no 45, pp. 280-283.

GUTIÉRREZ SOLER, Luis María (2011): Guía arqueológica de Giribaile, con la colaboración de Juan Carlos Castillo Armenteros, Jaén. 
HERNÁNDEZ GIMÉNEZ, Félix (1964): "Acerca de Majādat al-Fath y Saguyue en relación con la conquista de alAndalus", al-Andalus, XXIX-1, pp. 1-21.

HERNÁNDEZ JUBERÍAS, Julia (1996): La Península imaginaria. Mitos y leyendas sobre al-Andalus, Madrid.

JACINTO GARCÍA, E. J., (2006): "La toponimia de Jaén en las fuentes árabes medievales: aproximación lingüística”, Actas del XXXV Simposio Internacional de la Sociedad Española de Lingüística, ed. Milka Villayandre Llamazares, León, pp. 1004-1026.

LIROLA DELGADO, Jorge (2006): "Ibn Mahmūd al-Nafzī, "Ubaydīs", Biblioteca de al-Andalus, no 750, 4, Almería, pp. 61-63.

LIROLA DELGADO, Jorge (2012): "al-Bakrī, Abū "Ubayd". Biblioteca de al-Andalus, no 51, 1, Almería, pp. 154-160.

LIROLA DELGADO, Jorge (2012): "al-'Udrī, Abū l-'Abbās". Biblioteca de al-Andalus, no 1808, 7, Almería, pp. 559-570.

LOPEZ PINTO Gregorio, Historia apologética de la muy antiquísima ciudad de Cástulo...[Manuscrito] Copia digital: realizada por la Biblioteca de Andalucía Micro reproducción de: Manuscrito del s. XVII, (389 p.) MS 1251 Biblioteca Nacional.

MADOZ, Pascual (1851): Diccionario geográfico-estadístico-histórico de España y sus posesiones de Ultramar 6, Madrid.

MARÍN, Manuela, (1986): "IIm al-Nuŷūm e 'Ilm al-Hidțān en al-Andalus", Actas del XII congreso de la UEAI (Málaga, 1984), Madrid, pp. 509-535.

NAVARRO OLTRA, Vicente Carlos, "al-Himyarī, Abū 'Abd Allāh ibn al-Mun'im". Biblioteca de al-Andalus, no 152, 1, Almería, pp. 444-451.

PADILLA CERÓN, Andrés (2011): "Iglesias rurales, ermitas y capillas de Linares hasta el siglo XIX", Boletín del Instituto de Estudios Giennenses, n 203, pp. 225-262.

ROLDÁN CASTRO, Fátima (1990): El Occidente de alAndalus en el Ātār al-bilād de al-Qazwīnī, Sevilla.

ROLDÁN CASTRO, Fátima (1992): "El Oriente de al-Andalus en el Ätār al-bilād de al-Qazwin̄ī", Sharq al-Andalus. Estudios mudéjares y moriscos, nº 9, pp. 29-46.

RUS PUERTA, Francisco de (1634), Historia eclesiástica del reino y obispado de laen. Primera parte que contiene, sus principios, y progressos en la Religion Christiana. La predicación de los santos Apostoles lacobo, Pedro, y Paulo. Los santos, y martires, assi de Arjona, como de Baeça, y otros lugares. Los obispos de quien se halla memoria, la historia, tradicion y antiguedad de la Santa Veronica. Sitios de lugares antiguos. Con otras antiguedades dignas de ser sabidas. Desde el siglo primero de la Iglesia Christiana, hasta el duodecimo, Impreso por Francisco Perez de Castilla, Jaén.
SALVATIERRA CUENCA, Vicente (2001): La crisis del Emirato Omeya en el Alto Guadalquivir: Precisiones sobre la geografía de la rebelión muladí, Jaén.

SALVATIERRA CUENCA, Vicente (2006): El Alto Guadalquivir en época islámica, Jaén.

SALVATIERRA CUENCA, Vicente (2008): "Segura de la Sierra y el origen de la articulación de un territorio medieval", En Patrice Cressier (éd.), Le chateau et la ville. Espaces et réseaux, Castrum, 8, Madrid, pp. 135-150.

SÁNCHEZ LÓPEZ, Ángela; INFANTE LIMÓN, Enrique; VALIENTE ROMERO, Antonio, (2012): "La ermita de Santa Eufemia (Cástulo), un caso de experiencia tutelar del patrimonio arqueológico a mediados del siglo XVIII", Arqueología y Territorio Medieval, 19, pp. 147-166.

TERÉS, Elías, (1976): “Ubaydīs ibn Maḥmūd y Lubb ibn al-Šāliya, poetas de Šumuntān (Jaén)", al-Andalus, XLI-I, pp. 87-120.

TORRES BALBÁS, Leopoldo (1957): Ciudades yermas hispano-musulmanas, Maestre, Madrid.

VALLVÉ BERMEJO, Joaquín (1969): "La cora de Jaén", al-Andalus, XXXIV, pp. 55-82.

VALLVÉ BERMEJO, Joaquín (1975): "Una descripción de España de Ibn Gālib", Anuario de Filología, no 1, pp. 369-384.

VALLVÉ BERMEJO, Joaquín (1986): La división territorial de la España musulmana, CSIC, Madrid.

VAÑO SILVESTRE, Rafael (1970): "Oratorio Rupestre Visigodo del Cortijo de Valdecanales. Rus (Jaén)" Madrider Mitteilungen. Heidelberg F.H. Kerle no 11, pp. 213-222.

W.AA. (2002): "Torre de Santa Eufemia o Fortaleza de Cástulo o de Cazlona)" En Arquitectura de al-Andalus (Almería, Granada, Jaén, Málaga), Granada, pp. 709-711.

XIMENA JURADO, Martín de (1654), Catálogo de los obispos de las iglesias catedrales de Jaén y anales eclesiásticos de este obispado. Madrid, ed. facsímil (1991) con estudio preliminar e índices por J. Rodríguez Molina y Ma J. Osorio Pérez, Granada, Universidad de Granada y Ayuntamiento de Jaén. 